\title{
Impact of Obesity on Male Subfertility and Semen Quality: A Cross- Sectional Study
}

\author{
Medhat A. Saleh', Sahar A. Ismail², Hatem zedan² Ahmed S Gomaa² \\ ${ }^{1}$ Public Health and Community Medicine Department, ${ }^{2}$ Dermatology, Venereology and \\ Andrology Department, Faculty of Medicine, Assiut University. \\ Received: April $2016 \quad$ Accepted: June 2016
}

\begin{abstract}
:
Background: Relationship between obesity and male subfertility is a matter of controversial. Objective: To clarify relationship between obesity and male subfertility as well as confirm the relationship between BMI and quality of semen parameters. Methods: Study is observational cross-sectional, conducted in Department of Dermatology, Venereology and Andrology, Assiut University Hospital, between May and September 2015. Two hundred twenty males met our inclusion criteria were enrolled. Semen analysis was done to volunteers for follow up of their reproductive health after getting their consent. History taking, general and local genital examinations were done: participants were divided into 3 groups, group (I) normal weight (42), (II) overweight (104), (III) obese (94). Results: Mean BMI was $29.5 \pm 6.2$, semen volume was decreased from $3.3 \pm 1.2$ in normal weight to $2.9 \pm 1.45 \& 2.56 \pm 1.4$ in overweight and obese $(\mathrm{P}=0.02)$. Similar findings were reported in sperm concentration and count, while abnormal forms increased from $87.7 \pm 7.4$ in normal to $90.9 \pm 6.6 \& 91.6 \pm 8.1$ in overweight and obese $(\mathrm{P}=$ 0.04 . Motility decreased from $14.3 \pm 4.2$ in normal to $13.3 \pm 3.45 \& 11.8 \pm 5.4$ in overweight and obese $(\mathrm{P}=0.007)$, teratozoospermia index increased from $1.28 \pm 0.18$ in normal to $2.38 \pm 0.17$ and $3.29 \pm 0.22$ in overweight and obese $(\mathrm{P}=0.009)$, the same findings was observed in sperm deformity index. Conclusion: Obesity may play a negative role in sperm parameters and male subfertility.
\end{abstract}

Keywords: Obesity, infertility, BMI, Semen. Quality, Male.

Corresponding author: Medhat A. Saleh, Faculty of Medicine, Assiut University

\section{Introduction}

Infertility affects nearly $15 \%$ of married couples worldwide, and in $40 \%$ of them it is related to male factor. Assisted reproduction technology improved greatly the possibility for infertile couples to successfully conceive, but it does not mention the possible underlying cause of the couple's impaired fertility. Therefore identifying potential correctable risk factors for infertility may lead to more satisfactory and cost-effective approaches to optimizing fertility such as lifestyle modification, furthermore clarification of such risk factors would also supplement evidence for the mounting global efforts to encourage healthy lifestyles and disease prevention $\mathbf{1}$.

WHO in 2005 reported that approximately 1.6 billion adults were classified as overweight while 400 million adults were obese $^{2}$. This number increased to be 2.3 billion adults overweight and 700 million obese in 2015. The relationship between obesity and female subfertility has already been well established. It is well documented that obese females are more likely to experience both ovulatory and menstrual 
disorders, which usually lead to delayed fertility. Furthermore, obese women usually have poorer outcomes when undergoing fertility treatment, such as experiencing lower rates of pregnancy, increased likelihood of miscarriage and need higher gonadotrophins doses ${ }^{\mathbf{3}}$.

Male factor of infertility constitutes alone from $25-30 \%$ of all cases. Interestingly, there is evidence that quality of semen, measured primarily by sperm count, has declined to some extent in the latter half of the $20^{\text {th }}$ century ${ }^{4}$. Developed nations report a dramatic increase in prevalence of overweight and obesity, study of Danish couples reported an increased risk of subfertility with increasing weight in male partners, therefore it has been reported that obesity may represent a significant reversible cause of male subfertility ${ }^{\mathbf{3}}$.

Recent research into the relationship between body mass index (BMI) in obese couples and their semen parameters report conflicting results, early systematic review with meta-analysis suggest no relationship between these variables, On the other hand three large cross-sectional studies have found a significant negative relationship between BMI and sperm count or concentration ${ }^{6,7}$.

Considering the pathophysiology, a potential relationship between male subfertility and obesity is likely to be related to some mechanistic involvement of male reproductive hormones. It has already been established that obesity is usually associated with reductions in levels of many hormones as, total and free testosterone, and sex hormone-binding globulin (SHBG). Many studies have also reported elevated levels of estrogens in obese $\operatorname{men}^{\mathbf{8}}$. Another mechanism which has been reported in several studies to be more prevalent in obese men is erectile dysfunction ${ }^{9}$. Relationship between erectile dysfunction and high BMI can be partly due to increased level of several pro-inflammatory cytokines in obese persons which are positively associated with impaired endothelial function ${ }^{\mathbf{1 0}}$.

Many mechanisms may play a role in subfertility in obese males, both directly and indirectly, alterations in hormonal profiles (reduced androgen levels accompanied by elevated estrogen levels) and increased scrotal temperatures may play be one mechanism, impaired semen parameters (decreased total sperm count, concentration and motility; increased DNA fragmentation index) may be another mechanism (11). Furthermore, obesity can alter the physical and molecular structure of germ cells located in the testes of obese subjects and ultimately affects the maturity and function of sperm cells; moreover, obesity can cause hypoxia-induced apoptosis and endocrine disruption by obesogens. ${ }^{\mathbf{1 2}}$

Aim of the study: the study was aimed to clarify the relationship between obesity and male subfertility as well as confirm the relationship between BMI and quality of semen parameters

\section{Subjects and Methods}

The study is observational cross sectional study conducted in Department of Dermatology, Venereology and Andrology, Assiut University Hospital, between May and September 2015. This study included 240 fertile males met our inclusion and exclusion criteria as follows: sample size was calculated by Epi Tools epidemiological calculators for cross sectional studies at $95 \%$ confidence level, $80 \%$ power, ratio of exposed to unexposed 1 , and $15 \%$ percent of infertility among the Egyptian males ${ }^{\mathbf{1 3}}$. The calculated sample was 172 (86 in each group) and we raise the sample to 240 to get more informative results and allow studying different variables related to this issue.

Inclusion criteria: No history of fertility problems of the couples. The wife had a 
spontaneous pregnancy. The fertile male must either having a pregnant wife (more than 12 weeks) or just having a baby not more than 3 months.

Exclusion criteria: If the fertile man had any medical problem affecting fertility that occur after the conception eg: epididemoorchitis. Chemo or radiotherapy and history of any fertility treatment for any of the couple in the present conception.

Fertile men were recruited from Assiut University Hospital (AUN) during the duration of the study. An announcement was made asking fertile male volunteers to do semen analysis for follow up of their reproductive health and to assure future fertility. Announcement was directed to male partners come with their women who seeking medical consultations in ante-natal care, pediatric and vaccination clinics in AUN, as well as a very small number of employees from different departments of AUN who accept to participate in the study. According to BMI classification ${ }^{\mathbf{1 4}}$, the total 240 males were divided into three groups as follows: Group (1): Normal weight group: Included 42 participants with the normal range of BMI (18.5-24.99). Group (2): Overweight group: Included 104 participants who had BMI ranged (25.029.99). Group (3): Obese group: Included 94 participants with BMI $(\geq 30)$.

After obtaining their verbal consent for participation, all studied subjects (240) subjected to the following: History taking included age, residence, special habits (smoking), and fertility status. General examination included body built, musculature, hair distribution, fat distribution and gynecomastia. Local genital examination for testicular size, shape and consistency, epididymis, vas deferens, spermatic cord with stress on the presence or absence of varicocele. Semen analysis included: semen volume, $\mathrm{PH}$, viscosity, agglutination, sperm concentration, vitality (by hypo-osmotic swelling test), motility, morphology (by special stains for sperm morphology) and pus cells detection (by Peroxidase test).

Conventional semen analysis: Semen analysis was done after a sexual abstinence for at least 2 days but not more than 7 days. Semen was obtained by masturbation into a sterile plastic container. Samples were left to liquefy at $37^{\circ} \mathrm{C}$ and were analyzed just after liquefaction (within an hour) and all samples were examined according to the WHO, 1999 guidelines $^{15}$. Grade A motility was defined as a rapid progressive motility, grade B was classified as slow or sluggish linear motility, progressive motility included grade A and B. grade $\mathrm{C}$ is non-progressive motility and grade $\mathrm{D}$ was defined as immotile. Semen analysis done according to the criteria mentioned in the WHO laboratory manual for examining human semen ${ }^{\mathbf{1 4}}$. All samples were revised by two different trained technicians. Spermatozoon is considered normal when its head has a smooth oval configuration with well-defined acrosome comparing about $40-70 \%$ of the sperm head. Cytoplasmic droplers must not exceed $50 \%$ of the sperm head. Strict Tygerbirg criteria will be applied on all samples.

For indices of multiple sperm defects, the teratozoospermia index (TZI) which is the number of anomalies per each abnormal spermatozoon with a maximum of four defects is counted: one each for head, midpiece, and principal piece and one for excess residual cytoplasm. The normal range according to WHO manual (1999) is 1-3. The sperm deformity index (SDI) is the number of defects divided by the total number of spermatozoa; 1.6 is the cutoff point that maximized the sum of sensitivity and specificity. Special sheet for morphology had been made with examination of 100 sperms as follow: To minimize variations in the assessment of sperm characteristics, samples from all 
subjects were analyzed by the same well trained technicians using the same instruments and methods based on the WHO guidelines.

Ethical consideration: Verbal consent is obtained from all participants after explanation of all steps of the study, and it is explained to all participants that the collected data is confidential and for purpose of the scientific research only, furthermore, all investigations were free without any economic burden to the participants. Finally approval from the local ethical committee of Assiut Faculty of Medicine was obtained before conducting the practical work of the research.

Statistical analysis of the data: SPSS program (version 22) was used for data processing. Quantitative data was expressed in the form of mean \pm standard deviation (SD). ANOVA test were used to test the significance among groups. Duncan test was used to get the significance between groups (Multiple comparisons test). Person correlation test was applied to analyze correlations between different quantitative variables within each group. Probability level (P-value) was assumed significant if less than 0.05 .

\section{Results}

Table (1) shows that mean age was $33.8 \pm$ 7.3 , and age ranged from 20 to 55 years, mean weight was $83.7 \pm 16.5$, with a range from 50 to $161 \mathrm{Kg}$, while mean BMI of the participants was $29.5 \pm 6.2$. According to the results of table (2), 42 participants $(17.5 \%)$ have normal weight (group I), 104 (43.3\%) were overweight (group II), while 94 $(39.2 \%)$ were obese (group III).

Table (3): reveals a statistical significant relationships between grades of BMI and many semen parameters, as mean semen volume decreased significantly from $3.3 \pm$ $1.2(\mathrm{ml})$ in normal weight participants to 2.9 $\pm 1.45 \& 2.56 \pm 1.4$ in overweight and obese participants respectively $(\mathrm{P}=0.02)$. Similar findings was observed in sperm concentration $(40.19 \pm 1.2 \mathrm{million} / \mathrm{ml}$ in normal compared to $39.62 \pm 21.2$ and 31.74 \pm 17.3 in overweight and obese $(\mathrm{P}=<0.001)$. Total sperm count mean was markedly decreased from $124.1 \pm 60.2$ (million /ejc.) in normal to $107.3 \pm 74.5$ in overweight then to $76.4 \pm 51.8$ in obese $(\mathrm{P}=<0.001)$ (table 3). Also normal form (\%) of sperms decreased significantly from $11.9 \pm 4.3$ in normal weight group to $9.5 \pm 5.2$ and $9.5 \pm$ 5.2 in overweight and obese groups $(\mathrm{P}=$ $<0.001)$, while abnormal from $(\%)$ increased significantly from $87.7 \pm 7.4$ in normal weight to $90.9 \pm 6.6 \& 91.6 \pm 8.1$ in overweight and obese $(\mathrm{P}=0.02)$. Pus cells per million was increased from $0.33 \pm 0.1$ in normal to $(0.45 \pm 0.3 \& 0.64 \pm 0.2$ in overweight and obese $(\mathrm{P}=0.002)$. Finally, there was no statistically significant deference in head abnormality among the three groups.

Results presented in table 4 revealed a statistical significant relationships between grades of BMI and grade A and B sperm motility, as in grade $A$ : mean motility decreased from $14.3 \pm 4.2$ in normal weight participants to $13.3 \pm 3.45 \& 11.8 \pm 5.4$ in overweight and obese groups respectively $(\mathrm{P}=0.007)$, with a significant difference between the first two groups vs. the third group. Similar findings was observed in grade B: as mean motility decreased from $34.3 \pm 10.3$ in normal weight participants to $31.6 \pm 5.9 \& 30.6 \pm 9.3$ in overweight and obese participants respectively $(\mathrm{P}=0.003)$. Also, similar trend of previous results was noticed in Motility $\mathrm{C}$, these findings were confirmed when we compare motility A \& B in the three groups, as there was a linear trend of decrease motility when we move from normal to overweight and obese participants $(46.4 \pm 12.4,41.9 \pm 9.5$ and $40.4 \pm 12.7$ respectively $\mathrm{P}=<0.001$ ), while 
there was no statistical difference between the three groups in grades D motility.

Table (5) reveals a statistical significant relationships between all indices of multiple sperm defects and grades of BMI, as, Teratozoospermia index (TZI) which is defined as the number of abnormalities present per abnormal spermatozoon, teratozoospermia index (TZI) increased significantly from $1.28 \pm 0.18$ in normal participants to $2.38 \pm 0.17$ and $3.29 \pm 0.22$ in overweight and obese groups respectively $(\mathrm{P}=0.009)$. The same findings was observed in sperm deformity index (SDI), (a sperm morphological assessment by the strict Tygerberg's criteria for normal sperm morphology that was reported to correlate with fertilization rates which was increased significantly from $1.4 \pm 0.34$ in normal weight group to $1.7 \pm 0.38$ and $1.8 \pm 0.3$ in overweight and obese respectively $(\mathrm{P}=$ 0.003). While, Acro Index $\%$ show linear trend of decline (significantly) from normal to overweight and obese groups $(67.7 \pm 9.4$, $60.9 \pm 12.3$ and $58.3 \pm 13.6$ respectively $\mathrm{P}=$ $0.006)$.

\section{Discussion}

Worldwide prevalence of obesity has increased dramatically over the past two decades. the combined medical costs which attributed to obesity have increased by an estimated 2 billion $£$ /year. It was reported that obesity increases the risks of hypertension, diabetes, dyslipidemia, cardiovascular disease, osteoarthritis, and cancer, thereby elevating the rate of allcause mortality, the male fertility problems can cause around $30-40 \%$ of infertility ${ }^{\mathbf{1 5}}$.

Semen parameters evaluation in fertile men is important for proper assessment, counseling and treatment of men with infertility. Our results reveled that obesity reduced significantly many semen parameters, as mean semen volume, and total sperm concentartion/ejaculate were decreased significantly in obese participants, these results agreed with many authors, in Egypt $^{13}$, a study assessed the effect of obesity on seminal variables among 165 Egyptian fertile men and found that obesity decreased significantly sperm concentration, sperm motility and sperm normal morphology. Also, they found that BMI was negatively correlated with sperm concentration $(\mathrm{r}=-0.091 ; \mathrm{P}=0.014)$, progressive sperm motility $(\mathrm{r}=-0.697 ; \mathrm{P}=$ $0.001)$, normal sperm morphology $(\mathrm{r}=$ $0.51 ; \mathrm{P}=0.001)$ and sperm vitality $(\mathrm{r}=-$ $0.58 ; \mathrm{P}=0.001)$.

Another study in Egypt agreed with our findings ${ }^{17}$, which found that obesity has significant negative effects on semen parameters. The mechanism that may explain bad quality of semen parameters in obese subjects may be attributed to disturbance of sex hormones associated with increasing body weight especially decreasing serum Testosterone, LH and FSH; while, Prolactin level increased significantly with increasing BMI these hormonal changes may play important roles in changing quality of semen parameters in such patients. Furthermore, a retrospective analysis of data from 390 men suggested that high BMI was associated with reduction in sperm concentration and motility (18). These findings were confirmed by WHO surveillance study which stated that obese subjects had significantly lower total sperm count than non-obese men. However, other sperm parameters in such subjects were not shown to be affected ${ }^{\mathbf{1 9}}$.

A larger meta-analysis included 21 studies on over 13,000 men reported an evidence of a significant impact of obesity on spermatogenesis, and documented that obesity associated with both oligospermia and azoospermia. As odds ratio of oligospermia for overweight participants was 1.11 (1.01-1.21) and 1.28 (1.06-1.55) for obese men, rising to 2.04 (1.59-2.62) for 
morbidly obese ${ }^{5}$. Decrease in fertility parameters like sperm count and motility among obese men was also documented (20). Similar results were reported by ${ }^{\mathbf{2 1}}$ who found $21 \%$ and $23.9 \%$ reductions in sperm concentration and total sperm count in obese subjects compared to normal weight subjects.

On the other hand, we must mentioned that many obese men have been shown to have normal semen quality and fertility, suggesting that the effect of obesity on male subfertility in not consistent, as suggested by a study ${ }^{10}$ which found no association between obesity and semen quality. Also, a meta-analysis in 2010 mentioned that BMI has little or no relationship with sperm count and other sperm parameters ${ }^{22}$.

Our results also reveals that semen pus cells per million, sperm abnormal form percentage and semen pus cells/million increased significantly by increasing BMI (in group II and III). These results are in agreement with ${ }^{16}$ who found that obese men had higher abnormal sperm morphology and lower sperm vitality than normal weight subjects. Furthermore, obese men had significantly lower sperm normal forms than controls $^{23,}$ this study also stated that obese subjects had a significantly higher percentage of abnormal spermatozoa than normal weight and a higher number of spermatozoa with DNA fragmentation compared to normal weight.

Another important finding that supports this hypothesis is that an increase in DNA fragmentation index (DFI) was observed in men with high BMI, suggesting that obesity might compromise the integrity of sperm chromatin $^{24}$. It was also documented that any increase in BMI above $25 \mathrm{~kg} / \mathrm{m}^{2}$ causes an increase in sperm DFI and a decrease in the number of normal chromatin-intact sperm per ejaculate, relative to the degree of obesity and it may represent the reason of increasing sperm abnormality in obese men $^{25}$. On the other hand, another study found no statistically significant effect of male BMI was seen on semen parameters which are concentration, count, volume and motility $^{26}$. Regarding sperm motility, our results showed a significant decrease in sperm motility in overweight and obese groups (group II and III). These findings are agreed with many studies among these one study investigate this problem in Egyptian subjects and found that, obesity decreased significantly sperm motility in Egyptian patients ${ }^{17}$. These findings also agreed with ${ }^{23}$ who found that obese men had significantly lower sperm progressive motility than normal weight. In a study of 520 Danish men $^{24}$, a significantly reduction in number of normal motile sperms by increasing BMI of the participants was observed. These findings were confirmed by a powerful study of 526 sub-fertile men which stated that obese subjects have higher incidence of oligozoospermia with low progressive motile sperm concentration than in normal weight participants ${ }^{20}$. These changes in sperm motility in obese persons can be explained by the fact that obesity affects both sperm function and DNA quality ${ }^{(27)}$. It was reported that obesity could alter sperm function, in the form of increases sperm DNA damage, decreases sperm mitochondrial activity, induces seminal oxidative stress, and the presence of reactive oxygen species (ROS which is an indicator of perturbed mitochondrial function $^{28}$. Increased ROS were present in the semen of obese subjects, which appeared to be originated from blood macrophages. In rodent studies, high fat diet exposure also increased reactive oxygen species in sperm, an effect which also perturbed embryonic development. Furthermore, obesity impairs blastocyst development, reduces pregnancy outcome, or increases miscarriage following assisted reproduction these discrepancies likely represent differences in data 
acquisition, study populations, patient lifestyles, and comorbidities ${ }^{29}$.

Scrotum in obese subjects may predispose to increase in scrotal temperature, because it remains in closer contact with the surrounding tissue than in normal-weight subjects that may adversely affect semen parameters. Additionally, a study (30) reported that obesity may increase abdominal adiposity in men and subsequently associated with reduced sperm count, concentration, and motility. Furthermore, insulin resistance also is the other suggested mechanism to be associated with obesity and is a cause of hypoandrogenism and negatively correlated with testosterone levels. One of the explanations of the decreasing semen quality in obese men is the sexual hormonal disturbance that induced by obesity. A metaanalysis of these relationships confirmed the clear impact of increasing BMI on low testosterone level, and SHBG.

This may reflect the now well-recognized impact of energy sensing pathways on the kisspeptin/ neurokinin B pathways in the hypothalamus, which drive GnRH pulsatile secretion $^{31}$. Substantial effect of increasing BMI on male hormones including total and free testosterone, and SHBG at all ages was mentioned in many studies ${ }^{32}$. Furthermore, obesity, induce increase conversion of testosterone to estradiol, and the effect of this increase has an important role on suppressing gonadotropin release with subsequent suppression of spermatogenesis $^{33}$. Reproductive Biology Associates report that a high BMI in men correlates with reduced testosterone levels. One explanation of low Testosterone levels in obesity may be due to lower SHBG in such persons ${ }^{21}$.

Recent data stated that paternal obesity can negatively affect metabolic and reproductive systems of their offspring. Also, high-fat diets could affect the endocrine content of seminal fluid which may have very bad impact on early fetal development. Experimental and epidemiological data show that male fertility, and offspring health, can be improved by weight reduction in obese and overweight males ${ }^{34}$, because weight reduction is usually associated with rises in total testosterone, free testosterone, and $\mathrm{SHBG}^{35}$.

\section{Conclusion and recommendations:}

On the light of our results we conclude that overweight and obese men have an abnormal semen parameters summarized by decreased sperm concentration and count, decreased sperm motility as well as increase in semen pus cells and abnormal forms. Relationship between obesity and sperm parameters or male subfertility is likely to be multifactorial. Furthermore obesity has proved undesirable role in male fertility. Finally we recommend that we should incorporate weight reduction programs in all therapeutic strategies for male infertility, also we should increase the community awareness about the health hazards of obesity especially its impact on male subfertility.

\section{Conflict of interest:}

All authors declare that there is no conflict of interest regarding financial or other relationships in this research

\section{References}

1. Chambers GM, Sullivan EA, Ishihara O, Chapman MG, Adamson GD: The economic impact of assisted reproductive technology: a review of selected developed countries. Fertil Steril 2009 ;91:2291-2294.

2. WHO: Overweight and obesity. WHO: Geneva. Fact sheet 2006; no. 311.

3. Ramlau-Hansen CH, Thulstrup AM, Nohr EA, Bonde JP, Sørensen TIA, Olsen J: Subfecundity in overweight and obese couples. Hum Reprod 2007; 22: 1634-1637. 
4. Bonde JP, Ramlau-Hansen $\mathrm{CH}$, Olsen J: Trends in sperm counts: the saga continues. Epidemiology 2011; 22:617-619.

5. Sermondade N, Faure C, Fezeu L, Lévy $\mathrm{R}$, Czernichow S: Obesity and increased risk for oligozoospermia and azoospermia. Arch Intern Med. 2012;12;172 (5):440-2.

6. Aggerholm AS, Thulstrup AM, Toft G, Ramlau-Hansen $\mathrm{CH}$, Bonde JP : Is overweight a risk factor for reduced semen quality and altered serum sex hormone profile? Fertil Steril. 2014; 90:619-626.

7. Li Y, Lin H, Ma M, Li L, Cai M, Zhou N, Han X, Bao H, Huang L, Zhu C; Semen quality of 1346 healthy men, results from the Chongqing area of southwest China. Hum Reprod..2009; 24: 459-469.

8. MacDonald AA, Herbison GP, Showell M, Farquhar CM.: The impact of body mass index on semen parameters and reproductive hormones in human males: a systematic review with meta-analysis. Hum Reprod Update. 2010; 16:293-311.

9. Andersen I, Heitman BL, Wagner G: Obesity and sexual dysfunction in Younger Danish Men. J Sex Med 2008; 5:2053-60.

10. Pauli EM, Legro RS, Demers LM, Kunselman AR, Dodson WC, Lee PA: Diminished paternity and gonadal function with increasing obesity in men. Fertil. Steril. 2008; 90, 346-351.

11. Du Plessis SS, Cabler S, McAlister DA, Sabanegh E, Agarwal A.:The effect of obesity on sperm disorders and male infertility. Nat Rev Urol. 2010 ;7(3):153-61.

12. Shukla K. K.,. Chambial,. Dwivedi,. Misra and. Sharma : Recent scenario of obesity and male Fertility. Andrology, 2014; 2, 809-818

13. Taha EA, Sayed SK, Gaber HD, Abdel Hafez HK, Ghandour N, Zahran A, Mostafa T. : Does being overweight affect seminal variables in fertile men?. Reprod Biomed Online. 2016; Sep 16. pii: S14726483(16)30507-7.
14. WHO, : BMI classification. 2004; http://apps.who.int/bmi/index.jsp?introPage =intro_3.html.

15. World Health Organization. WHO laboratory manual for the examination of human semen and semen-cervical mucus interaction. 4th ed. Cambridge, UK: Cambridge University Press; 1999.

16. Mara, Y., J. Roth, K. Amory and T.P. Stephanie: Treatment of male infertility secondary tomorbid obesity. Nature Clinical PracticalEndocrinology and Metabolism, 2008 ; 4 (7): 415-419.

17. Abdullah A. and S. Bakry.: Obesity and Infertility in Egyptian Men. Research Journal of Medicine and Medical Sciences, 2008; 3(2): 135-139.

18. Hammoud AO, Wilde N, Gibson M, Parks A, Carrell DT, Meikle AW: Male obesity and alteration in sperm parameters. Fertil Steril; 2008; 90: 2222-2225.

19. Stewart TM, Lui DY, Garrett C : Associations between andrological measures, hormones and semen quality in fertile Australian men: inverse relationship between obesity and sperm output. Hum Reprod : 2009;1:1-8.

20. Najafi M, kavitha P, Sreenivasa G, Chaithra PT, Vineeth VS and Malini SS: Overweight and obese me are more prone to infertility- Myth or fact. 2011; Journal of paramedical sciences Vol.2, No.4.

21. Jensen, T.K., A.M. Andersson, N. Jorgensen, A.G.Andersen, E. Carlsen, J.H. Petersen.: Bodymass index in relation to semen quality andreproductive hormones among 1,558 Danish men.Fertil. Steril., 2004; 82: 863-70

22. Carlsen E, Giwercman A, Keiding N, Skakkebaek NE. Evidence for decreasing quality of semen during past 50 years. BMJ: 1992; 305: 609-13.

23. La Vignera S, Condorelli RA, Vicari E, Calogero AE: Negative effect of increased body weight on sperm conventional and 
nonconventional flow cytometric sperm parameters. J Androl; 2012; 33:53-8.

24. Kort, H.I., J.B. Massey, C.W. Elsner, Mitchell-Leef D., D.B. Shapiro, M.A. Witt : Impact of body mass index values on sperm quantity andquality. J. Androl., 2006; 27:450-2.

25. Macdonald AA1, Stewart AW, Farquhar CM : Body mass index in relation to semen quality and reproductive hormones in New Zealand men: a cross-sectional study in fertility clinics. Hum Reprod.: 2013;Dec;28(12):3178-87.

26. Thomsen Lise, Peter Humaidan, Leif Bungum, Mona Bungum: The impact of male overweight on semen quality and outcome of assisted reproduction. Asian Journal of Andrology: 2014; 16, 749-754

27. Palmer NO, Bakos HW, Fullston T, Lane M.: Impact of obesity on male fertility, sperm function and molecular composition. Spermatogenesis; 2012;2:253-63.

28. Aitken RJ, Smith TB, Jobling MS, Baker MA, De Iuliis GN: Oxidative stress and male reproductive health. Asian $\mathbf{J}$ Androl: 2014; 16: 31-38.

29. Umul M, K€ose SA, Bilen E, Altuncu AG, Oksay T, G€uney M.: Effect of increasing paternal body mass index on pregnancy and live birth rates in couples undergoing intracytoplasmic sperm injection. Andrologia; 2015; 47:360-4.
30. Hammiche F, Laven JS, Twigt JM, Boellaard WP, Steegers EA, SteegersTheunissen RP. : Body mass index and central adiposity are associated with sperm quality in men of subfertile couples. Hum Reprod: 2012;27: 2365-72.

31. Roa J, Tena-Sempere M : Connecting metabolism and reproduction: roles of central energy sensors and key molecular mediators. Mol Cell Endocrinol : 2014; 397: 4-14.

32. Wu FCW, Tajar A, Pye SR, Silman AJ,x : Hypothalamic-pituitary-testicular axis disruptions in older men are differentially linked to age and modifiable risk factors: the European Male Aging Study. J Clin Endocrinol Metab: 2008; 93: 2737-2745.

33. Nguyen, R., A. Wilcox, R. Skjaerven, D. Baird: Men's body mass index and infertility. Hum.Reprod. 2007; 22: 2488-93. 34. Rastrelli G, Carter EL, Ahern T : Development of and Recovery from Secondary Hypogonadism in Ageing Men: Prospective Results from the EMAS. J Clin Endocrinol Metab 2015; 100 : 3172-3182. 35. Camacho EM, Huhtaniemi IT, O'Neill T. W.: Age-associated changes in hypothalamic-pituitarytesticular function in middle-aged and older men are modified by weight change and lifestyle factors: longitudinal results from the European Male Ageing Study. Eur J Endocrinol Eur Fed Endocr Soc : 2013; 168: 445-455. 
Table (1): Demographic characteristics of the studied sample.

\begin{tabular}{|l|c|r|r|}
\hline Grades of BMI & Mean \pm SD & \multicolumn{1}{|c|}{ Minimum } & \multicolumn{1}{c|}{ Maximum } \\
\hline Age & $33.8 \pm 7.3$ & 20 & 55 \\
\hline Weight & $83.7 \pm 16.5$ & 50 & 161 \\
\hline Height & $168.6 \pm 7.5$ & 150 & 188 \\
\hline Body mass index & $29.5 \pm 6.2$ & 19.81 & 59.86 \\
\hline
\end{tabular}

Table (2): Grades of body mass index of the studied sample.

\begin{tabular}{|l|r|r|}
\hline Grades of BMI & No. & \% \\
\hline Normal weight & 42 & 17.5 \\
\hline Overweight & 104 & 43.3 \\
\hline Obese & 94 & 39.2 \\
\hline Total & $\mathbf{2 4 0}$ & $\mathbf{1 0 0 . 0}$ \\
\hline
\end{tabular}

Table (3): Relationship between grades of BMI and semen parameters in the studied sample.

\begin{tabular}{|c|c|c|c|c|c|}
\hline \multirow[b]{2}{*}{ Parameter } & \multicolumn{3}{|c|}{ Grads of BMI } & \multirow[b]{2}{*}{$\begin{array}{c}\text { Total } \\
(\mathbf{N}=\mathbf{2 4 0})\end{array}$} & \multirow[b]{2}{*}{$\begin{array}{c}\text { P. value } \\
\text { (Sig.) }\end{array}$} \\
\hline & $\begin{array}{l}\text { Group (I) } \\
\text { Normal } \\
(\mathrm{N}=42)\end{array}$ & $\begin{array}{c}\text { Group (II) } \\
\text { Overweight } \\
(\mathrm{N}=104)\end{array}$ & $\begin{array}{c}\text { Group (III) } \\
\text { Obese } \\
(\mathrm{N}=94)\end{array}$ & & \\
\hline Semen volume (ml) & $3.3^{\mathrm{a}} \pm 1.2$ & $2.9^{\mathrm{a}} \pm 1.35$ & $2.56^{\mathbf{b}} \pm 1.4$ & $2.8 \pm 1.3$ & $0.002 * *$ \\
\hline Sperm conc. (million/ml) & $40.2^{\mathrm{a}} \pm 19.1$ & $39.6^{\mathrm{a}} \pm 21.2$ & $31.7^{\mathbf{b}} \pm 17.3$ & $36.6 \pm 20.3$ & $<0.001 * *$ \\
\hline Total sperm count (million /ejc.) & $124.1^{\mathrm{a}} \pm 60.2$ & $107.3^{\mathrm{a}} \pm 74.5$ & $76.4^{\mathbf{b}} \pm 51.8$ & $98.6 \pm 66.2$ & $<0.001 * *$ \\
\hline Pus cells per million & $0.33^{\mathbf{c}} \pm 0.1$ & $0.45^{b} \pm 0.3$ & $0.64^{\mathrm{a}} \pm 0.2$ & $0.44 \pm 0.1$ & $0.002 * *$ \\
\hline Normal form (\%) & $11.9^{\mathrm{a}} \pm 4.3$ & $9.5^{\mathbf{b}} \pm 5.2$ & $8.8^{\mathbf{b}} \pm 3.7$ & $10.3 \pm 4.9$ & $<0.001 * *$ \\
\hline Abnormal form (\%) & $87.7^{\mathbf{b}} \pm 7.4$ & $90.9^{\mathrm{a}} \pm 6.6$ & $91.6^{\mathbf{a}} \pm 8.1$ & $89.7 \pm 7.1$ & $0.021 *$ \\
\hline Pus cells per million & $0.33^{\mathbf{c}} \pm 0.1$ & $0.45^{b} \pm 0.3$ & $0.64^{\mathrm{a}} \pm 0.2$ & $0.44 \pm 0.1$ & $0.002 * *$ \\
\hline Head abnormality & $1.29 \pm 0.6$ & $1.3 \pm 0.6$ & $1.45 \pm 0.8$ & $1.35 \pm 0.7$ & $0.23^{\mathrm{NS}}$ \\
\hline
\end{tabular}

ANOVA and Duncan tests were used.

Means in the same raw which share the same superscript symbol are not significantly different.

** Significant $(p<0.01) \quad * \quad$ Significant $(p<0.05) \quad$ NS $\quad$ Not significant 
Table (4): Relationship between grades of BMI and Sperm motility in the studied sample.

\begin{tabular}{|c|c|c|c|c|c|}
\hline \multirow[b]{2}{*}{$\begin{array}{l}\text { Grades of sperm } \\
\text { motility }\end{array}$} & \multicolumn{3}{|c|}{ Grads of BMI } & \multirow[b]{2}{*}{$\begin{array}{c}\text { Total } \\
(\mathrm{N}=\mathbf{2 4 0})\end{array}$} & \multirow{2}{*}{$\begin{array}{l}\text { P. value } \\
\text { (Sig.) }\end{array}$} \\
\hline & $\begin{array}{l}\text { Normal } \\
(\mathrm{N}=42)\end{array}$ & $\begin{array}{l}\text { Overweight } \\
(\mathrm{N}=104)\end{array}$ & $\begin{array}{l}\text { Obese } \\
(\mathrm{N}=94)\end{array}$ & & \\
\hline Motility grade A & $14.3^{\mathrm{a}} \pm 4.2$ & $13.3^{a} \pm 3.45$ & $11.8^{\mathbf{b}} \pm 5.4$ & $14.4 \pm 6.3$ & $0.007 * *$ \\
\hline Motility grade B & $34.3^{a} \pm 10.3$ & $31.6^{b} \pm 5.9$ & $30.6^{\mathbf{b}} \pm 9.3$ & $32.4 \pm 8.3$ & $0.003 * *$ \\
\hline Motility grade $\mathrm{C}$ & $14.7^{\mathrm{a}} \pm 4.5$ & $11.9^{\mathbf{b}} \pm 4.1$ & $11.4^{b} \pm 4.0$ & $13.0 \pm 4.2$ & $<0.001 * *$ \\
\hline Motility grade D & $39.7 \pm 10.7$ & $40.2 \pm 9.9$ & $39.7 \pm 8.2$ & $39.9 \pm 9.1$ & $0.56^{\mathrm{NS}}$ \\
\hline Motility grade A \& B & $46.4^{\mathrm{a}} \pm 12.4$ & $41.9^{b} \pm 9.5$ & $40.4^{\mathbf{b}} \pm 12.7$ & $43.3 \pm 11.9$ & $<0.001 * *$ \\
\hline
\end{tabular}

ANOVA and Duncan tests were used.

Means in the same raw which share the same superscript symbol are not significantly different.

Table (5): Relationship between grades of BMI and indices of multiple sperm defects in the studied sample.

\begin{tabular}{|c|c|c|c|c|c|}
\hline \multirow{2}{*}{$\begin{array}{l}\text { Indices of multiple sperm } \\
\text { defects }\end{array}$} & \multicolumn{3}{|c|}{ Grads of BMI } & \multirow{2}{*}{$\begin{array}{c}\text { Total } \\
(\mathrm{N}=\mathbf{2 4 0})\end{array}$} & \multirow{2}{*}{$\begin{array}{l}\text { P. value } \\
\text { (Sig.) }\end{array}$} \\
\hline & $\begin{array}{l}\text { Normal } \\
(\mathrm{N}=42)\end{array}$ & $\begin{array}{l}\text { Overweight } \\
\qquad(\mathrm{N}=104)\end{array}$ & $\begin{array}{l}\text { Obese } \\
(\mathrm{N}=94)\end{array}$ & & \\
\hline Teratozoospermia IndexTZI (\%) & $1.28^{c} \pm 0.18$ & $2.38^{\mathbf{b}} \pm 0.17$ & $3.29^{\mathrm{a}} \pm 0.22$ & $1.3 \pm 0.19$ & $0.009 * *$ \\
\hline Sperm Deformity Index SDI (\%) & $1.4^{\mathbf{b}} \pm 0.34$ & $1.7^{\mathrm{a}} \pm 0.38$ & $1.8^{\mathrm{a}} \pm 0.3$ & $1.6 \pm 0.3$ & $0.003 * *$ \\
\hline Acro Index (\%) & $67.7^{a} \pm 9.4$ & $60.9^{b} \pm 12.3$ & $58.3^{b} \pm 13.6$ & $60.6 \pm 14.2$ & $0.006 * *$ \\
\hline
\end{tabular}

ANOVA and Duncan tests were used.

Means in the same raw which share the same superscript symbol are not significantly different. 